\title{
El patrimonio contemporáneo en la ciudad histórica de Sevilla. La protección del Movimiento Moderno (1925-1975) desde el planeamiento urbanístico
}

O patrimônio contemporâneo na cidade histórica de Sevilha. A proteção do Movimento Moderno (1925-1975) por meio do planejamento urbano

Contemporary heritage in the historic city of Seville. The preservation of the Modern Movement (1925-1975) through urban planning

Juan-Andrés Rodríguez-Lora[a] (D), Daniel Navas-Carrillo[a] (D), María Teresa Pérez-Cano[a] (D)

[a] Universidad de Sevilla, Departamento de Urbanística y Ordenación del Territorio, Sevilla, Andalucía, España

Cómo citar: Rodríguez-Lora, J.-A., Navas-Carrillo, D., \& Pérez-Cano, M. T. (2021). El patrimonio contemporáneo en la ciudad histórica de Sevilla. La protección del Movimiento Moderno (1925-1975) desde el planeamiento urbanístico. urbe. Revista Brasileira de Gestão Urbana, 13, e20200153. https://doi.org/10.1590/2175-3369.012.e20200153

\section{Resumen}

El concepto de patrimonio no ha dejado de evolucionar desde principios del siglo XX hasta la actualidad. Entre otros avances, se ha conseguido superar el valor de antigüedad como criterio principal a la hora de considerar un elemento como patrimonio. Como consecuencia, ha surgido el concepto de patrimonio contemporáneo para referirse al proceso de patrimonialización de edificios construidos a lo largo de los siglos XIX y XX, incluidos los surgidos del Movimiento Moderno (1925-1975). El presente artículo estudia la evolución en el reconocimiento de este patrimonio emergente en el caso de Sevilla, la capital de Andalucía (España). Su protección es analizada desde un enfoque eminentemente urbano, a través del instrumento urbanístico de Plan Especial de Protección. La investigación se centra en analizar la inserción progresiva del patrimonio contemporáneo en el planeamiento urbanístico de protección, en base al año en que se desarrolla el plan para cada sector de la ciudad (26 sectores en total). En consecuencia, el trabajo identifica las principales diferencias entre la salvaguarda del patrimonio ya consolidado y el patrimonio contemporáneo como un problema. La menor protección de este último supone un mayor riesgo de pérdida de valores y de su desaparición.

Palabras clave: Movimiento Moderno. Patrimonio contemporáneo. Planeamiento Especial de Protección. Sevilla. Urbanismo.

\section{Resumo}

O conceito de patrimônio não deixou de evoluir desde o início do século XX até hoje. Entre outros avanços, foi possível ultrapassar o valor da antiguidade como critério principal ao considerar um elemento como patrimônio. Como consequência, surgiu o conceito de patrimônio contemporâneo, que defende o processo de patrimonialização dos edifícios construídos ao longo dos séculos XIX e XX, incluindo os que surgiram do Movimento Moderno (1925-1975). Este artigo centra-se na evolução do reconhecimento desse patrimônio emergente em Sevilha, capital da Andaluzia (Espanha). A sua proteção é analisada a partir de uma abordagem eminentemente urbana, por meio do instrumento de planejamento urbano do "Plano de

JARL es máster, e-mail: jrodriguez91@us.es

DNC es doctor Arquitecto, e-mail: dnavas@us.es

MTPC es doctora Arquitecta, e-mail: tpcano@us.es 
Proteção Especial". A investigação centra-se na análise da inserção progressiva do patrimônio contemporâneo no planejamento de proteção urbana, com base no ano em que foi desenvolvido o plano para cada setor da cidade (26 setores no total). Consequentemente, o trabalho identifica as principais diferenças de salvaguarda do patrimônio consolidado e do patrimônio contemporâneo como um problema, especialmente para aqueles em risco de desaparecer.

Palavras-chave: Movimento Moderno. Patrimônio contemporâneo. Planejamento de proteção especial. Sevilha. Urbanismo.

\section{Abstract}

The concept of heritage has not stopped progressing since the beginning of the 20th century until today. Among other advances, it has managed to overcome the historic value of antiquity as the main criteria used for considering an element as heritage. As a result, the concept of contemporary heritage has emerged to refer to the patrimonialization process of buildings constructed throughout the 19th and 20th centuries. It includes those that emerged from the Modern Movement (1925-1975). This work analyzes the evolution in recognition of this emerging heritage in the case of Seville, the Andalusian capital (Spain). Its preservation was analyzed from an urban eminent approach, through the urban planning instrument of special preservation plan. The research focuses on analyzing the progressive insertion of contemporary heritage into the urban preservation planning, based on the year in which the plan for each sector of the city is developed (26 sectors in total). Consequently, the work identified the main criteria differences in safeguard of both consolidated and contemporary heritage as a problem, especially in the case of those at risk of disappearing.

Keywords: Modern Movement. Contemporary heritage. Special protection planning. Seville. Urbanism.

\section{Introducción}

El siglo XX se ha caracterizado por ser el periodo en el cual las ciudades han experimentado, en general, un mayor crecimiento respecto a etapas anteriores, con una producción arquitectónica que supera a lo construido con anterioridad (García-Gutiérrez Mosteiro, 2011). No sólo el crecimiento de la ciudad ex novo ha sido característica, sino que las transformaciones de la trama de la ciudad heredada y conjuntos históricos, para la apertura de calles y espacios públicos, han marcado el devenir de éstas en el pasado siglo. En este escenario, proliferaron las edificaciones proyectadas y construidas bajo conceptos y/o principios modernos.

La investigación asume la evolución conceptual experimentada por la noción de patrimonio a lo largo del siglo XX, superando sus consideraciones iniciales en torno al monumento como elemento aislado. Así como, en la concepción patrimonial actual, trasciende también del valor histórico o de antigüedad como el principal criterio en el que articular la protección. Con ello no se trataría de reconocer como patrimonio unos edificios por su envejecimiento, sino por ser un testimonio valioso de un fragmento destacado del siglo XX (Pérez Escolano, 1999).

Como se dilucida de las líneas previas, se hace una aproximación a la arquitectura contemporánea del siglo XX, entendida como objeto patrimonial. Una visión que podría ir a contracorriente de algunos de los principios modernos o la crítica antimonumental de diversos autores modernos (De Jonge, 2017) pero que, bajo las consideraciones actuales y la evolución antes mencionada del concepto de patrimonio, suponen un reto para la sociedad del siglo XXI.

La producción arquitectónica moderna quedaría fijada a partir del año 1925. Esta fecha se encuentra designada en diversas fuentes, reflejando la practicidad y convencionalismo a la hora de referirse a una etapa histórica. Esto no significa que sea un límite estanco en el que comienza toda esta actividad moderna. En este sentido, Carlos Flores López (1989) señalaría 1925 como fecha en la que comienzan a tener mayor importancia las nuevas ideas. Igualmente, destacaría el registro Docomomo como referencia 
para fijar la fecha de inicio. Esta organización, que abarcaba el periodo 1925-1965, en su filial Ibérica (Docomomo Ibérico, 2020) ha ampliado recientemente el mismo hasta 1975. La ampliación se justifica en el desarrollo tardío experimentado por la producción moderna de ambos países, coincidiendo además con el final de los regímenes autoritarios en España y Portugal. Es por ello que la etapa de estudio seleccionada para la presente investigación comprende el periodo 1925-1975.

Consecuentemente, la presente investigación aborda, desde una perspectiva urbana, la protección de este patrimonio del Movimiento Moderno de Sevilla. Patrimonio presumiblemente menos protegido por las herramientas urbanísticas competentes en materia patrimonial, frente a los edificios de mayor recorrido histórico. Cuestión que puede repercutir en pérdidas irreparables de sus valores o en la desaparición de estos edificios.

\section{Evolución del reconocimiento del patrimonio contemporáneo en Europa, España y Andalucía}

Son varias las muestras de evolución en torno al patrimonio a lo largo del siglo XX. Así lo demuestran las numerosas Cartas, Declaraciones y Documentos internacionales publicadas. Estos documentos vendrían a articular una serie de criterios con los que abordar la cuestión patrimonial, en las cuáles se evidencian las múltiples aperturas que se han ido realizando en el concepto Patrimonio. La preocupación por la desaparición de la producción arquitectónica del siglo XX se produciría antes de que el propio siglo finalizara.

En este sentido y partiendo del ámbito europeo, un hito a destacar es la reunión de expertos en patrimonio que se produce en el año 1971 en Praga. Este encuentro contaría con la colaboración de la UNESCO y el patrocinio de las instituciones de la denominada en ese momento Checoslovaquia. Con el fin de abordar en claves patrimoniales la producción de bienes del siglo XIX y XX, se reunirían múltiples representantes de ICOMOS, además de otros entendidos en la materia de 11 países europeos. La congregación, a propósito de este patrimonio, surge a raíz de la especial preocupación que rodea al estado de conservación y las desapariciones producidas en este conjunto de bienes realizados en este periodo. Todo ello propiciando, en propias palabras del documento oficial de la Declaración de Praga de 1971, la primera ocasión para debatir sobre monumentos artísticos y culturales contemporáneos (Praga, 1971). Entre otras cuestiones, destaca el reconocimiento como un problema real la desprotección que tiene el patrimonio contemporáneo a escala mundial.

Por otro lado, en el año 1990, mediante la Declaración de Eindhoven (Docomomo, 1990), se produce la fundación de la organización sin ánimo de lucro Docomomo. Organización que nace como reacción a la desaparición progresiva de edificios nacidos a partir del Movimiento Moderno y que tiene un papel fundamental en la difusión de esta arquitectura (Navas-Carrillo, 2020). El periodo temporal y la arquitectura sobre la que se centra es en la producida en torno al Movimiento Moderno. Cabría destacar el nacimiento en 1993 de la filial para la Península Ibérica (España y Portugal), centrada en los elementos construidos situados en estos dos países.

Un año después, en 1991, el Comité de Ministros de la Unión Europea (Europa, 1991) pone de manifiesto la preocupación existente a nivel de las instituciones europeas con relación al déficit de atención y protección que sufre la Arquitectura Contemporánea. Es entonces cuando se publica la Recomendación no (91) 13 sobre la protección del patrimonio arquitectónico del siglo XX. En este documento, entre otras muchas reivindicaciones y motivaciones, destaca la inquietud que supone perder el legado y patrimonio que fue producido en el seno de Europa cuando se iba consolidando las relaciones entre los Estados, erigiéndose como arquitectura simbólica de este proceso.

Como ya se vería en la Declaración de Praga, la falta de reconocimiento patrimonial no sucede solo con la arquitectura del siglo XX, sino también con la del XIX. Hecho que se evidenciaba en una menor presencia en las listas patrimoniales a nivel global. Dicho desequilibrio fue detectado por la UNESCO en 1994, momento en que empieza a plantear una serie de medidas para moderar dicho problema. Por este 
motivo, la UNESCO desarrolló un programa específico para atender a todas estas carencias en torno a la arquitectura de los siglos XIX y XX al que denominaría como "Patrimonio Moderno". A propósito de este, se publicó un documento dedicado a la arquitectura, urbanismo y paisajismo del periodo señalado y que conformaría el ejemplar "World Heritage Papers" no 5 (UNESCO, 2003).

Finalmente, como hito reciente en todo este cometido, la UNESCO e ICOMOS, organismo consultivo habitual, crean el Comité Científico Internacional del Patrimonio del Siglo XX conocido como ISC20C (International Scientific Committee on 20th Century Heritage). Éste abarca exclusivamente el siglo XX, pero en su totalidad, hecho que contrasta con lo planteado por Docomomo. El ISC20C (2011) insta a la patrimonialización y protección de todos los edificios realizados a lo largo del siglo XX en su conjunto, superando así reconocer una sola expresión arquitectónica y aceptando la heterogeneidad y multiplicidad de casos que se dieron a lo largo del pasado siglo. Igualmente, cabe destacar el papel fundamental que juega el Getty Conservation Institute (GCI) en la defensa del patrimonio contemporáneo. A través de su programa Conserving Modern Architecture Initiative (CMAI), el instituto Getty aboga por avanzar en su conservación, así como, en su difusión a través de programas de formación y publicaciones (Getty Conservation Institute, 2018).

No obstante, a pesar de los avances señalados en cuanto al reconocimiento internacional de esta arquitectura, son bienes que continúan teniendo un mayor riesgo de desaparición que sus predecesores (Tostões, 2015). La problemática que rodea al patrimonio contemporáneo edificado se verá acentuada para el caso de los espacios públicos propios de este periodo. Sin embargo, la conformación del concepto de paisaje cultural se presenta como una oportunidad para reconocer los valores de estos espacios públicos, los cuáles trascienden a su condición propia como tal, erigiéndose, en casos como las intervenciones de Roberto Burle Marx en Río de Janeiro, como patrimonio paisajístico contemporáneo (Rey Pérez \& Tabacow, 2013).

Para el caso español, resulta interesante la revisión de los cambios que a nivel legislativo se producen en torno a la apertura a nuevas formas patrimoniales. A través de las distintas leyes de patrimonio aprobadas durante el siglo XX es posible aproximarse a los cambios conceptuales experimentados en el concepto Patrimonio.

La inserción del término "monumento" en la legislación española data de 1803 con la promulgación de la Cédula de Carlos IV (Fariña Tojo, 2000). Desde entonces, son varios los avances que se darían hasta llegar a la Ley para la Defensa, Conservación y Acrecentamiento del Patrimonio Histórico Artístico Nacional de 1933. El análisis parte de ésta por ser coetánea al objeto de estudio, así como, por su longeva vigencia. Permanecería en vigor -con modificaciones- hasta la ley de 1985. De este modo estará presente en tres etapas diferenciadas de la historia reciente de España: se dicta durante la II República, continúa durante la Dictadura y llega hasta los primeros años de la actual Democracia.

El patrimonio contemporáneo encontraría serias dificultades para ser amparado y protegido por esta ley de 1933 como así muestra el siguiente fragmento de su artículo 1o: "[...] de antigüedad no menor de un siglo; también aquellos que sin esta antigüedad tengan un valor artístico o histórico indiscutible, exceptuando, naturalmente las obras de autores contemporáneos [...]" (España, 1933, p. 1394).

En consecuencia, la edad de la edificación era un primer obstáculo para su protección. Solo con la primera condición quedaba excluida toda la producción arquitectónica del siglo XX, así como un importante número del siglo anterior. La segunda limitación temporal, en caso de que se hiciera una excepción con la primera, vendría fijada por la condición de que el artífice de la obra no podía seguir vivo. De este modo, se aseguraba que el valor principal fuera el histórico, con objeto de que el tiempo que hubiera pasado fuese significativo para la patrimonialización del edificio. Los conceptos "histórico", "artístico" y "cultural" también se incluyen en la Constitución Española de 1978, dando continuidad, por tanto, a los ya definidos en la ley de 1933 (España, 1933).

Es con la aparición de la Ley de Patrimonio Histórico Español de 1985 cuando se hace efectiva la supresión de la limitación temporal explícita que restringía las posibilidades de protección de la arquitectura contemporánea. Bien es cierto que se mantiene indirectamente una acotación temporal, buscando con ello evitar la protección de los bienes más cercanos en el tiempo, aunque con ciertas 
aperturas tal como se define en el punto cuarto de su artículo noveno: "No podrá ser declarada Bien de Interés Cultural la obra de un autor vivo, salvo si existe autorización expresa de su propietario o media su adquisición por la Administración". Algo reseñable de esta ley es el reconocimiento del patrimonio inmaterial, lo cual denota la evolución experimentada hasta este momento por el concepto de patrimonio.

Centrando la atención en Andalucía, y tras el traspaso de las competencias en materia de patrimonio cultural a las Comunidades Autónomas en 1984, se aprueba la primera Ley de Patrimonio Histórico de Andalucía en 1991 (Andalucía, 1991). En base a los avances dados por la mencionada ley estatal, da un paso adicional al suprimir las delimitaciones temporales, tanto en lo referido a la edad de la edificación como a la condición de vida de sus autores. La ley andaluza vigente de 2007 (Andalucía, 2007), consolida la superación de los límites marcados por su predecesora y refunda la catalogación de los bienes con dos niveles: Bien de Interés Cultural y Catalogación General.

Cabría destacar el papel del Instituto Andaluz del Patrimonio Histórico (IAPH). Esta entidad, dependiente de la Consejería de Cultura y Patrimonio Histórico de la Junta de Andalucía, es responsable de múltiples acciones de la más diversa índole en torno a los Bienes Culturales. En cuanto al patrimonio contemporáneo, sobresale la elaboración de una base de datos dedicada expresamente a los inmuebles del siglo XX (Rodríguez-Lora et al., 2018). El Registro Andaluz de la Arquitectura Contemporánea (RAAC), actualmente integrado en la Guía Digital del Patrimonio Cultural de Andalucía, aglutina edificios de las múltiples expresiones arquitectónicas que se dieron desde 1900 al año 2000. Como hito reseñable de protección de la arquitectura contemporánea en Andalucía, cabe reseñar la resolución de 2001 de la Dirección General de Bienes Culturales, en la que se incluyeron dieciséis inmuebles que se encontraban registrados en Docomomo Ibérico (Becerra García, 2012).

\section{Patrimonio contemporáneo en entornos históricos}

El presente artículo se centra en el estudio de edificios patrimoniales del siglo XX en Sevilla, con un Conjunto Histórico significativo, tanto por su recorrido histórico como por su dimensión, si bien existen otras muchas urbes históricas situadas en un contexto cercano caracterizadas por una similar casuística. Es el caso de la producción de Rafael de La-Hoz y José María García de Paredes en el Conjunto Histórico de Córdoba, declarado Patrimonio Mundial, en la que destaca edificios como la Cámara de Comercio. Relaciones simbióticas entre la producción arquitectónica y su emplazamiento en la ciudad histórica como la que se produce entre el edificio de la Compañía Granadina o el Cine Generalife en el Conjunto Histórico de Granada o el edificio de viviendas y locales comerciales de Alejandro de la Sota en el centro histórico de Salamanca.

En cuanto al estudio, difusión y reconocimiento de esta arquitectura destacan investigaciones singulares como la mirada patrimonial de estos edificios a través de la dupla arquitectura-cine (Alonso García et al., 2018). En el contexto europeo, son notables las labores realizadas en Francia, con el uso del distintivo "Label XX", o de los Países Bajos, en el que además de situar el origen de Docomomo, cabe reconocer el esfuerzo realizado en el registro y posterior protección, tanto a nivel estatal como municipal, de la producción arquitectónica, urbanística y artística del denominado periodo de la reconstrucción.

Ahora bien, más allá de los avances producidos en el reconocimiento de esta arquitectura, la presente investigación no ha identificado estudios de similar naturaleza, es decir, enfocados en el análisis de la protección otorgada a la arquitectura del siglo XX por el planeamiento urbanístico, desde una perspectiva urbana de conjunto, o circunscritos a su inserción en la trama histórica. 


\section{El uso del planeamiento especial de protección para la salvaguarda del patrimonio}

En base a la Ley 14/2007 del Patrimonio Histórico de Andalucía, la tutela del patrimonio cultural de Andalucía queda bajo responsabilidad de distintos niveles administrativos. En cualquier caso, como indica Becerra García (2012, p. 19):

La Ley 14/2007, de 26 de noviembre, del Patrimonio Histórico de Andalucía, establece, en su artículo 29, que los instrumentos de ordenación territorial y urbanística que incidan sobre bienes integrantes del patrimonio histórico, con independencia de que se encuentren protegidos mediante resolución expresa o simplemente se encuentren identificados como patrimonio histórico en inventarios o publicaciones [...] Y que en el caso de los planes urbanísticos, los elementos patrimoniales se deben incorporar al catálogo urbanístico.

En consecuencia, a la protección de los edificios declarados Bien de Interés Cultural (BIC) o Inscritos en el Catálogo General del Patrimonio Histórico Andaluz, se suma la labor realizada por los ayuntamientos a través del planeamiento urbanístico.

Los Catálogos de Protección insertos en las figuras de planeamiento existentes son una herramienta clave en la tutela de este patrimonio. La trascendencia de estos documentos es producto de haber sido redactados desde un prisma de cercanía frente a lo que sucede con la administración regional o estatal. Cabe resaltar que es la administración local la que tiene un contacto próximo con los bienes que componen el núcleo urbano que gestiona. Estos Catálogos pueden incluirse en otras figuras urbanísticas, destacando el rol que ejercen en los denominados Planes Especiales de Protección. Cabe señalar que según el artículo 14 de la Ley de Ordenación Urbanística de Andalucía (Andalucía, 2002), son instrumentos urbanísticos cuya finalidad es conservar, proteger y mejorar el medio ambiente urbano y, principalmente, el patrimonio portador o expresivo de los valores urbanos, arquitectónicos, históricos o culturales de una determinada área urbana. Por tanto, la investigación los toma como referencia en el análisis de la ciudad objeto de estudio.

\section{El caso de Sevilla}

Sevilla es una ciudad histórica localizada en Andalucía, región situada al sur de España, siendo en la actualidad la Comunidad Autónoma más poblada y la segunda más extensa del país. Como capital de Andalucía, Sevilla es la ciudad con más habitantes de la región, con una población censada-año 2019- de 688.592 habitantes (INE, 2020). Cabe señalar el periodo analizado como uno de los de mayor incremento de población experimentado por la ciudad. Pasa de 205.723 habitantes en 1920 (IECA, 2020) a 545.692 en 1970 (IECA, 2020), llegando a triplicarse en 1981 con 645.817 habitantes (IECA, 2020). Desde ese momento, se inicia un periodo en el que el crecimiento ha sido más moderado.

En este contexto, la ciudad de Sevilla, al igual que tantas otras urbes, ha sufrido importantes modificaciones a lo largo del pasado siglo. Cambios que no solo devendrían de la necesidad de dar cabida al crecimiento de población previamente señalado (Navas-Carrillo et al., 2019), sino también a través de diversas transformaciones sobre la trama urbana heredada. Destaca así la redacción de múltiples figuras de planeamiento que propondrían modificaciones sobre la morfología de la ciudad, como las Ordenanzas Municipales, los Planes de Ordenación Urbanística y, en especial, el Plan de Reforma Viaria, buscando actualizar la ciudad a los requerimientos de la sociedad de la época. Crecimientos y modificaciones de la pasada centuria, tales como la apertura entre 1906 y 1927 de la actual Avenida de la Constitución (Tejido Jiménez, 2016) o el ensanchamiento de la Calle Imagen iniciado en 1955 (Fernández Salinas, 1992), que favorecieron la construcción de edificios que respondían a conceptos modernos.

Así, la presente investigación aborda una muestra de 44 edificios (Tabla 1) localizados dentro del Conjunto Histórico de Sevilla. Elementos cuyos valores patrimoniales y reconocimiento quedan atestiguados al formar parte de los distintos registros especializados que han sido elaborados hasta la fecha, de los cuales se ha extraído la totalidad de casos de la muestra analizada. 
Tabla 1 - Edificios de la muestra analizada

\begin{tabular}{|c|c|c|}
\hline Denominación & Año & Autoría \\
\hline \multicolumn{3}{|l|}{ Sector 01} \\
\hline $\begin{array}{l}\text { Casa de pisos para Manuel Moreno } \\
\text { Felipe }\end{array}$ & 1937 & Rafael Arévalo Carrasco, Gabriel Lupiáñez Gely \\
\hline Casa para Manuel Moreno Felipe & 1939 & Rafael Arévalo Carrasco, Gabriel Lupiáñez Gely \\
\hline $\begin{array}{l}\text { Cinematógrafo Bécquer } \\
\text { Sector } 03\end{array}$ & 1940 & Rodrigo Medina Benjumea \\
\hline $\begin{array}{l}\text { Grupo escolar Huerta de Santa Marina } \\
\text { Sector } 05\end{array}$ & 1934 & Leopoldo Carrera Díez, Juan Talavera y Heredia \\
\hline $\begin{array}{l}\text { Cinematógrafo y viviendas Florida } \\
\text { Sector } 06\end{array}$ & 1941 & Rafael Arévalo Carrasco, Gabriel Lupiáñez Gely \\
\hline $\begin{array}{l}\text { Escuela maternal María Inmaculada } \\
\text { Sector } \mathbf{0 7}\end{array}$ & 1932 & Juan Talavera y Heredia \\
\hline Casa Lastrucci & 1934 & Antonio Delgado Roig, Juan Talavera y Heredia \\
\hline $\begin{array}{l}\text { Casa de pisos para José Lozano } \\
\text { González }\end{array}$ & 1934 & José Galnares Sagastizábal \\
\hline $\begin{array}{l}\text { Edificio de viviendas y locales } \\
\text { comerciales }\end{array}$ & 1935 & José Galnares Sagastizábal, A. Wespi Schneider \\
\hline \multicolumn{3}{|l|}{ Sector 08.1} \\
\hline Edificio Caja San Fernando & 1957 & Rafael Arévalo Carrasco, Ignacio Costa Vals \\
\hline $\begin{array}{l}\text { Edificio de oficinas y locales comerciales } \\
\text { en Imagen }\end{array}$ & 1958 & Ricardo Espiau Suárez de Viesca \\
\hline Edificio de Oficinas en Imagen & 1960 & Ricardo Espiau Suárez de Viesca \\
\hline $\begin{array}{l}\text { Viviendas en Doña María Coronel } \\
\text { Sector } \mathbf{0 8 . 2}\end{array}$ & 1974 & Antonio Cruz Villalón, Antonio Ortiz García - (Cruz y Ortiz) \\
\hline $\begin{array}{l}\text { Jefatura Superior de Policía de la } \\
\text { Gavidia }\end{array}$ & 1962 & Ramón Montserrat Ballesté \\
\hline \multicolumn{3}{|l|}{ Sector 08.3} \\
\hline Auto Ibérica & 1927 & Antonio Gómez Millán, Aurelio Gómez Millán \\
\hline Edificio de viviendas en Laraña & 1957 & Luis Gómez Estern \\
\hline Edificio de oficinas en Plaza Nueva & 1961 & Ricardo Abaurre y Herreros de Tejada, Luis Díaz del Río \\
\hline Tienda Loewe & 1963 & Francisco Javier Carvajal Ferrer \\
\hline Edificio Banco de Granada & 1968 & José María García de Paredes Barreda \\
\hline \multicolumn{3}{|l|}{ Sector 08.4} \\
\hline Cabo Persianas & 1940 & Rafael Arévalo Carrasco, Gabriel Lupiáñez Gely \\
\hline Conjunto residencial Virgen del Carmen & 1960 & Luis Recasens Méndez-Queipo de Llano \\
\hline $\begin{array}{l}\text { Edificio de viviendas y oficinas en la } \\
\text { Magdalena }\end{array}$ & 1968 & Rafael Arévalo Camacho, Luis Marín de Terán \\
\hline $\begin{array}{l}\text { Edificio de viviendas en Pedro del Toro } \\
\text { Sector } 09\end{array}$ & 1971 & José Ramón Sierra Delgado, Ricardo Sierra Delgado \\
\hline Edificio de viviendas en Torneo & 1944 & Alberto Balbontín de Orta, Antonio Delgado Roig \\
\hline $\begin{array}{l}\text { Edificio de viviendas en Medina } \\
\text { Sector } 14\end{array}$ & 1974 & Antonio Cruz Villalón, Antonio Ortiz García - (Cruz y Ortiz) \\
\hline $\begin{array}{l}\text { Grupo escolar en Procurador } \\
\text { Sector } 16\end{array}$ & 1934 & Leopoldo Carrera Díez, Juan Talavera y Heredia \\
\hline Escuela infantil de la Santísima Trinidad & 1937 & $\begin{array}{c}\text { Antonio Delgado Roig, Leopoldo Carrera Díez, Juan Talavera y } \\
\text { Heredia }\end{array}$ \\
\hline $\begin{array}{l}\text { Guardería y consultorio puericultura } \\
\text { Sector } 18\end{array}$ & 1937 & Rafael Arévalo Carrasco, Gabriel Lupiáñez Gely \\
\hline Mercado de la Puerta de la Carne & 1927 & Aurelio Gómez Millán, Gabriel Lupiáñez Gely \\
\hline Casa para Joaquín Álvarez Mellado & 1934 & Joaquín Díaz Langa, Luis Fernando Gómez-Estern Sánchez \\
\hline $\begin{array}{l}\text { Ambulatorio Nuestra Señora Esperanza } \\
\text { Macarena } \\
\text { Sector } 19\end{array}$ & 1964 & Fernando García Mercadal \\
\hline $\begin{array}{l}\text { Sector } 19 \\
\text { Nave de fundición de cañones }\end{array}$ & & \\
\hline $\begin{array}{l}\text { Nave de fundición de cañones } \\
\text { Sector } 20\end{array}$ & 1930 & Desconocido \\
\hline $\begin{array}{l}\text { Viviendas y estación de autobuses } \\
\text { Sector } 22\end{array}$ & 1938 & Rodrigo Medina Benjumea \\
\hline Viviendas en el Prado de San Sebastián & 1951 & $\begin{array}{l}\text { Luis Fernando Gómez-Estern Sánchez, Felipe Medina Benjumea, } \\
\text { Rodrigo Medina Benjumea, Alfonso Toro Buiza }\end{array}$ \\
\hline Edificio de viviendas para militares & 1969 & $\begin{array}{l}\text { Felipe Medina Benjumea } \\
\text { Luis Fernando Gómez-Estern Sánchez, Felipe Medina Benjumea, }\end{array}$ \\
\hline Sede Social Sevillana (Endesa) & 1970 & $\begin{array}{l}\text { Ángel Orbe Caro, Manuel Trillo de Leyva, Fernando Villanueva } \\
\text { Sandino }\end{array}$ \\
\hline
\end{tabular}


Tabla 1 - Continuación...

\begin{tabular}{|c|c|c|}
\hline Denominación & Año & Autoría \\
\hline \multicolumn{3}{|l|}{ Sector 23} \\
\hline $\begin{array}{l}\text { Edificio del reloj pirotecnia militar } \\
\text { (reforma) }\end{array}$ & 1940 & Juan Talavera y Heredia \\
\hline \multicolumn{3}{|l|}{ Sector 24} \\
\hline Villa Donostia & 1932 & José Granados de la Vega \\
\hline Villa Moya & 1933 & José Granados de la Vega \\
\hline Viviendas para Trueba y Pardo & 1940 & José Manuel Bringas Vega \\
\hline Casa para Fausto Antonio Moya & 1941 & José Granados de la Vega \\
\hline $\begin{array}{l}\text { Sede del Colegio de Médicos } \\
\text { Sector } 25\end{array}$ & 1972 & Rafael de La-Hoz Arderius, Gerardo Olivares James \\
\hline $\begin{array}{l}\text { Casa para la sra. viuda de Lasarte } \\
\text { Sector } \mathbf{2 6}\end{array}$ & 1939 & Luis Fernando Gómez-Estern Sánchez, Alfonso Toro Buiza \\
\hline Hotel Palace Eritaña & 1928 & Gabriel Lupiáñez Gely \\
\hline
\end{tabular}

Fuente: Elaborado por los autores (2020) en base a la publicación "50 años de Arquitectura en Andalucía: 1936-1986" (Pérez Escolano et al., 1986), "Cien años de arquitectura en Andalucía" (Fernández-Baca Casares \& Pérez Escolano, 2012) y el registro Docomomo lbérico.

\section{Metodología}

La investigación se ha estructurado en cuatro fases. En primer lugar, se ha realizado una búsqueda de todos los edificios patrimoniales, o susceptibles de ser considerados como tal, construidos dentro del periodo de estudio definido (1925-1975). Para llevar a cabo este cometido se han seleccionado y revisado aquellas fuentes bibliográficas de mayor interés y recorrido en la materia, así como, las bases de datos especializadas en patrimonio contemporáneo disponibles. En concreto, se han manejado las publicaciones "50 Años de Arquitectura en Andalucía: 1936-1986" (Pérez Escolano et al., 1986), "La Vanguardia Imposible: quince visiones de arquitectura contemporánea" (Mosquera Adell \& Pérez Cano, 1990) y "Cien años de arquitectura en Andalucía. El Registro Andaluz de Arquitectura Contemporánea, 1900-2000" (Fernández-Baca Casares \& Pérez Escolano, 2012), así como las bases de datos o registros Docomomo Ibérico y el Registro Andaluz de Arquitectura Contemporánea -integrado en Guía Digital del Patrimonio Cultural de Andalucía- (Andalucía, 2020a). A partir de éstas, se construye una base de datos propia que sintetiza y actualiza la información obtenida del conjunto de referencias analizadas. Una vez superada la visión del patrimonio desde criterios histórico-artísticos y monumentalista, su evolución conceptual ha permitido definir otra serie de valores que vendrían a amparar a las creaciones del siglo XX. Así, en el Documento de Madrid (ISC20C, 2011) se habla de valores de ubicación, de diseño, constructivos, usos, etc. Por su parte, el Plan Nacional de Conservación del Patrimonio Cultural del siglo XX (España, 2015) considera valores patrimoniales la autenticidad, integridad, valores técnicos, singularidad, cultural-estético, entre otros. En este sentido, a la hora de configurar la muestra de análisis, la investigación no ha tenido solo en cuenta criterios estilísticos circunscritos al lenguaje moderno, siendo éste de especial interés, sino que se le sumarían criterios como la autoría, el uso, constructivos y singularidad.

Seguidamente, se ha identificado el grado de protección de los edificios objeto de estudio. Para ello, ha sido imprescindible consultar el Catálogo General del Patrimonio Histórico de la Consejería de Cultura y Patrimonio Histórico de la Junta de Andalucía (2020b), el Plan General de Ordenación Urbanística de Sevilla (Sevilla, 2006), así como, los Planes Especiales de Protección -PEP- de los 26 sectores que conforman el Conjunto Histórico de Sevilla (Sevilla, 2020). Cabe destacar que se ha profundizado en estos últimos. En concreto, se han analizado los Catálogos de Protección que consignan los planes previamente señalados (Sevilla, 2020). Con el fin de organizar la investigación, se ha optado por manejar cada sector del Conjunto Histórico como una unidad de análisis.

En la tercera fase, una vez identificada la totalidad de edificios patrimoniales, se geolocalizan sobre la trama urbana de Sevilla (Rodríguez-Lora, 2018). Esto se ha llevado a cabo mediante el uso de Sistemas de Información Geográfica (SIG). De este modo, a la vez que cada edificio se ha situado en la ciudad, se ha creado una base de datos con las características e información principal de cada uno de ellos. La base 
gráfica urbana del trabajo se ha constituido a partir de la descarga y manejo de capas de información obtenidas de múltiples bases de datos geográficos de carácter público, entre las que destaca el geoportal de Infraestructuras de Datos Espaciales de Andalucía -IDEAndalucía- (Andalucía, 2020c). A ello se sumaría la creación de nuevas capas, generando cartografías propias, las cuáles no se entienden como objetivo último, sino como una herramienta de investigación más.

Finalmente, la última fase es de carácter analítico. En este caso, una vez obtenida una base de datos propia y representada en el espacio urbano, se realizan análisis pormenorizados sobre la protección patrimonial a partir de la totalidad de edificios considerados en la investigación, con el fin de tener una visión de conjunto respecto a su posición en la ciudad, eludiendo, de este modo, la visión unitaria de cada edificio individualizado. Como previamente se ha indicado, no sólo se trata de localizar estos inmuebles en la trama urbana, sino que, la información obtenida de la revisión bibliográfica y documental realizada, ha permitido obtener datos y protección de cada uno de ellos, caracterizándose, así, la muestra estudiada. Con toda esta información se han obtenido conclusiones sobre la inserción de éstos en los Planes Especiales, extrayendo cual ha sido la evolución sobre el proceso de patrimonialización de estos edificios en el caso de Sevilla.

\section{La protección urbanística del patrimonio contemporáneo en Sevilla}

\section{El patrimonio contemporáneo en los sectores del Conjunto Histórico de Sevilla}

La considerable extensión del Conjunto Histórico de Sevilla hace que se subdivida administrativamente en sectores, entendidos como barrios, fragmentándose la ciudad histórica en porciones más reducidas. Dicha subdivisión es deudora de las divisiones medievales de carácter administrativo-religioso, de modo que numerosos sectores actuales se corresponden con las collaciones históricas de la ciudad (Sarabia Sánchez, 1998). Esta organización de la ciudad facilita el desarrollo del Planeamiento Especial de Protección, coincidiendo la delimitación de estos planes con la división en sectores. A partir de estos, la investigación trata de ordenar y sistematizar la información extraída (Figura 1 y Figura 2).

Dicho Conjunto Histórico está conformada por un total de veintiséis sectores, algunos subdivididos en varios subsectores, entre los cuales nueve de ellos $(2,4,10,11,12,13,15,17$ y 21) no contienen entre sus límites ningún edificio de los consignados en los registros de arquitectura contemporánea. La mayoría de estos nueve sectores corresponden a las zonas de borde de la ciudad histórica, o bien, son los de menor extensión. El sector que aglutina mayor número de inmuebles de patrimonio contemporáneo es el número 8 que, a pesar de subdividirse en cuatro, abarca un total de catorce edificios. Es en este sector donde, en cierta medida, se reflejan los considerables cambios a nivel urbanístico que supusieron la apertura de nuevas calles y la redefinición de la trama urbana con el afán de introducir el uso del coche en la ciudad heredada. Es por ello que en la calle Imagen y, en general, en el eje este-oeste que divide el centro histórico en dos, se localizan un número considerable de edificios modernos de interés patrimonial.

Por otro lado, el sector 24 es el siguiente en cuanto a mayor número de edificios contemporáneos, siendo en este caso una zona más vinculada con el crecimiento sur de la ciudad por la Exposición Iberoamericana de 1929. En el siguiente escalón, con tres edificios, nos encontramos los sectores 1 en la zona norte de la urbe histórica, el 7, siendo una zona de alta carga patrimonial con dos de los edificios declarados Patrimonio Mundial por la UNESCO -Catedral y Archivo de Indias- y de mayor afluencia turística en la actualidad, el 18 en la conformación de la Ronda Histórica y el 22 como zona vinculada al crecimiento sur extramuros. Aquellos sectores en los que solo se localiza un edificio de interés con vinculaciones al Movimiento Moderno se encuentran mayoritariamente en los bordes del conjunto. Al igual que ocurre con los nueve sectores que carecen de inmuebles incluidos en los registros de 
patrimonio contemporáneo analizados, los sectores que se sitúan en el borde del Conjunto Histórico son los que incorporan un menor número de ejemplos, mientras que los que se encuentran en el corazón del centro histórico son los que más ejemplos aportan a la investigación.

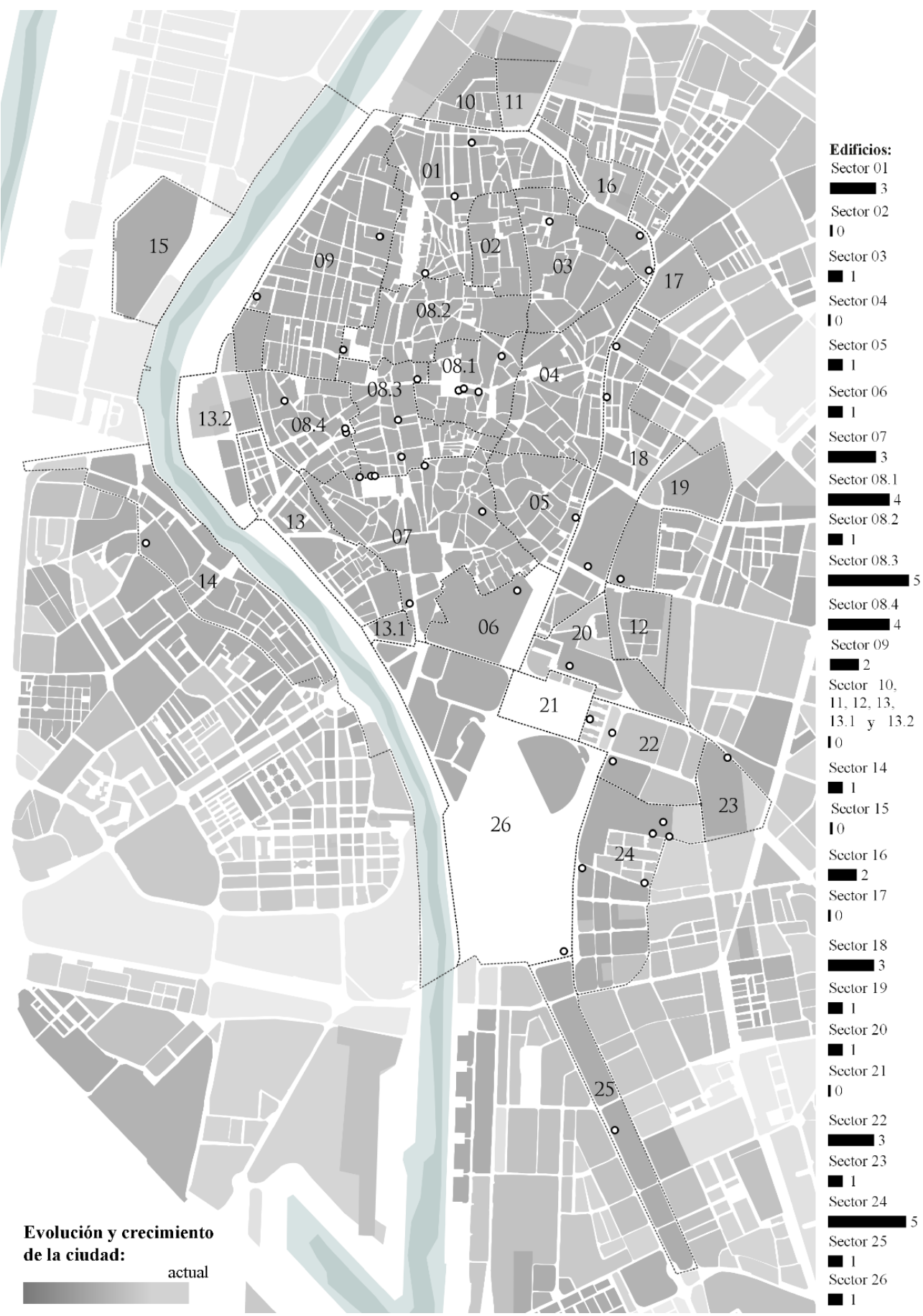

Figura 1 - Sectores del Conjunto Histórico de Sevilla y localización de edificios del Movimiento Moderno (19251975). Fuente: Realizado por los autores (2020) en base a los Planes Especiales de Protección de los sectores y Plan General de Ordenación Urbanística de Sevilla de 2006. 


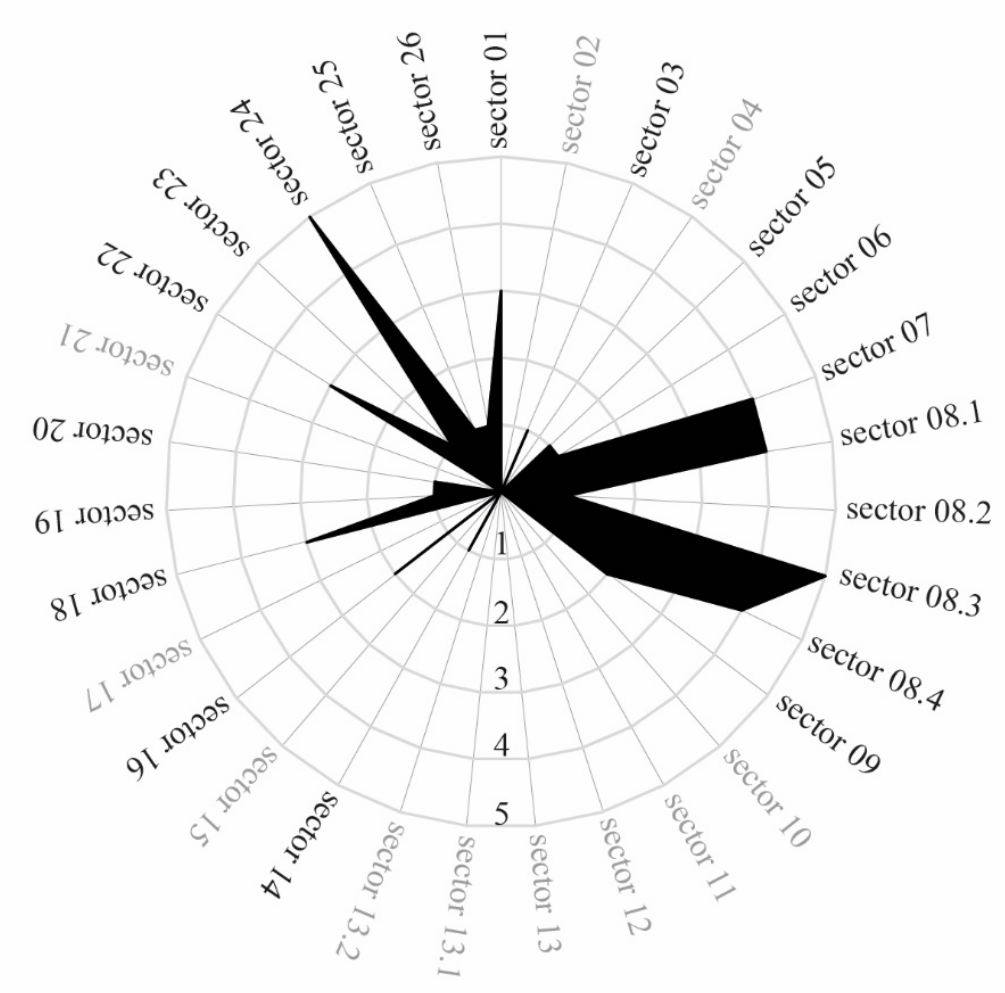

Figura 2 - Diagrama de edificios por sectores. Fuente: Autores (2020)

La protección del patrimonio contemporáneo según el Plan Especial de Protección de cada sector del Conjunto Histórico

Tras la aproximación a la división que configura el Conjunto Histórico de la ciudad, se analiza el Plan Especial de Protección de cada sector, atendiendo especialmente a la inclusión de elementos representativos de arquitectura contemporánea en sus catálogos de protección. Estos planes han sido redactados y publicados en diferentes años e incluso existen casos de sectores que actualmente no cuentan con esta figura de planeamiento aprobada, como el Sector 7, a pesar de la importancia patrimonial de la zona, o, a lo sumo, un documento de avance de este. Esto sucede con el sector 6 "Real Alcázar", que delimita el conjunto de edificios y jardines de este Bien Cultural que, junto a la Catedral y el Archivo de Indias, fue declarado Patrimonio Mundial por la UNESCO en 1987. En este último caso, a pesar de no contar con la aprobación definitiva, se ha tomado como referencia la protección que el documento realiza sobre el edificio incluido en la base de datos manejada.

Cabría destacar que los Catálogos de estos planes establecen cinco niveles de protección según un gradiente conformado por letras en orden alfabético que van desde la $A$, siendo la máxima protección, hasta la E (Tabla 2). Estos grados serían los siguientes: A (Protección Integral), B (Protección Global), C (Parcial en Grado 1), D (Parcial en Grado 2) y E (Protección Ambiental). Este último grado desaparece en algunos de los Planes Especiales de Protección más actuales, acorde con el Plan de Ordenación Urbanística de 2006, pero es considerado para la investigación al estar presente en tantos otros. 


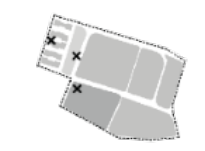

Sector 22. PEP 1994

3 edificios, 0 protegidos

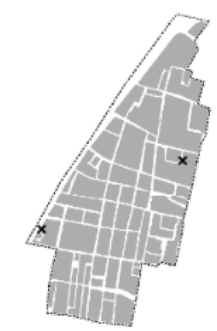

Sector 09. PEP 2000

2 edificios, 0 protegidos

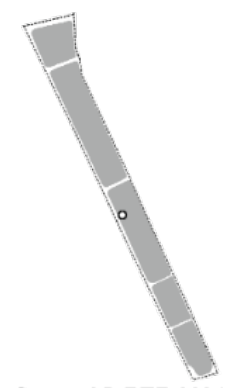

Sector 25. PEP 2004 1 edificio, 1 protegido

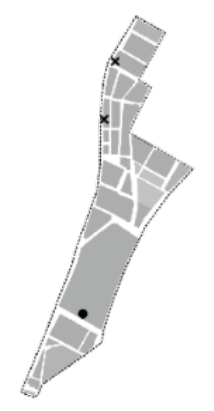

Sector 18. PEP 1995

3 edificios, 1 protegido

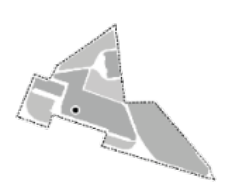

Sector 20. PEP 1996 1 edificio, 1 protegido

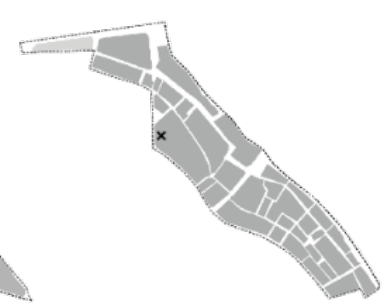

Sector 14. PEP 1999 1 edificio, 0 protegidos

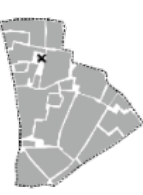

Sector 03. PEP 2000 1 edificio, 0 protegidos

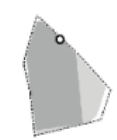

Sector 23. PEP 2002

1 edificio, 1 protegido

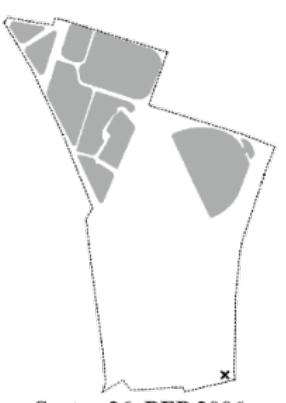

Sector 26. PEP 2006

I edificio, () protegidos

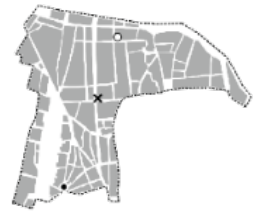

Sector 01. PEP 2002

3 edificios, 2 protegidos

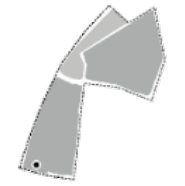

Sector 19. PEP 2010

1 edificio, 1 protegido

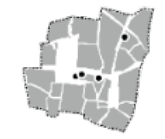

Sector 08.1. PEP 2014 4 edificios, 4 protegidos

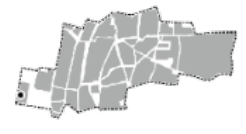

Sector 08.2. PEP 2013 1 edificio, 1 protegido

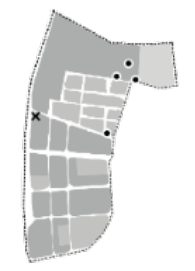

Sector 24. PEP 2003

5 edificios, 4 protegidos

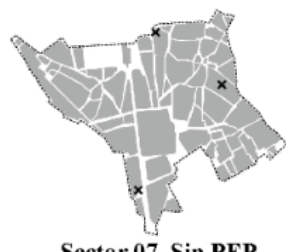

Sector 07. Sin PEP

3 edificios, 0 protegidos

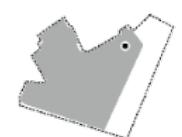

Sector 06. PEP 2010

(sin aprobación)

1 edificio, 1 protegido
Nivel de protección

- A

- B

- C

- D

- E

$\times$ Sin protección

Conjunto Histórico

-....... Sector

Figura 3 - Edificios por sector y su nivel de protección a través del Planeamiento Especial de Protección (PEP). Fuente: Realizado por los autores (2020) en base a los Planes Especiales de Protección

La autonomía a la hora de proteger este patrimonio, debido al hecho de que cada sector cuente de manera independiente con un Plan Especial de Protección, produce que se presenten diferencias en cuanto a la protección del patrimonio contemporáneo. En estas discrepancias, debe considerarse el 
desfase temporal entre la redacción y aprobación de los distintos Planes, lo que inexorablemente genera diferencias en los criterios utilizados y, por tanto, en las tipologías catalogadas. Se debe tener en cuenta que la investigación abarca dos décadas de redacción de planeamiento especial. Se parte de la aprobación del plan del sector 22 en 1994, finalizando con la aprobación en 2014 del plan del subsector 8.1. En este sentido, la evolución en la consideración patrimonial de esta arquitectura, cuestión expresada a lo largo del presente documento, no solo se refleja, como anteriormente se indicó, en los primeros registros, sino también a través del análisis realizado sobre los Planes Especiales de Protección.

Tabla 2 - Niveles de Protección establecidos en el planeamiento

\begin{tabular}{cc}
\hline Nivel & Intervenciones posibles \\
\hline A: Integral & Solo conservación \\
B: Global & $\begin{array}{c}\text { Conservación y cambio de uso de parte o totalidad del edificio manteniendo las } \\
\text { características originales del edificio }\end{array}$ \\
C: Parcial grado 1 & $\begin{array}{c}\text { Mantenimiento de edificabilidad actual con la posibilidad de aumentar un porcentaje de esta } \\
\text { con el fin de permitir la posible adaptación de las edificaciones a las exigencias actuales }\end{array}$ \\
D: Parcial grado 2 & $\begin{array}{c}\text { Protección de la fachada y de la primera crujía del edificio. La edificabilidad que se le asigna } \\
\text { es la de nueva planta, incluyéndose en esta la materializada por los elementos protegidos } \\
\text { Control en la sustitución de estos edificios por otros nuevos. La edificabilidad que se le asigna } \\
\text { es la de nueva planta, incluyéndose en esta la materializada por los elementos protegidos }\end{array}$ \\
\hline
\end{tabular}

Fuente: Elaborado por los autores (2020) en base al Plan General de Ordenación Urbanística de Sevilla (2006)

De dicho análisis, se desprende que la labor de redacción de Planes Especiales comienza por los sectores con menor carga patrimonial histórica. El primero en aprobarse es el del sector 22 en 1994, en el cual no se protege ningún edificio de la muestra dado que, en el momento en que se redacta, todos los edificios son de una construcción relativamente reciente. Por tanto, no se protege ni los que muestran estética moderna ni los de corte más historicista, a pesar de que estos últimos habitualmente encuentran mayor grado de aceptación entre algunos sectores de la sociedad.

A nivel global, se observa cómo la tendencia a no proteger este patrimonio contemporáneo se alarga hasta el año 2002 inclusive, donde se percibe cierta predisposición a la protección de estos edificios en los sucesivos planes aprobados, alcanzando su consolidación a partir del año 2010.

La redacción y aprobación del Plan General de Ordenación Urbanística (PGOU) en el año 2006, supuso una oportunidad para revisar la protección que estos edificios pudieran tener en los Planes Especiales previos a dicho PGOU. Con la creciente consideración de la arquitectura del siglo XX como patrimonio cultural son diversos los edificios que verían modificada su protección, evidenciándose este hecho a la vista de los cambios entre la Figura 3 y la Figura 4. Cabe destacar, igualmente, la protección de algunos elementos situados tanto en el sector 7 que no cuenta con Plan Especial de Protección, como en el 6 con el Plan Especial redactado pero sin aprobación definitiva.

\section{Resultados}

Una vez revisada la protección otorgada por los Planes Especiales, y lo que significan sus niveles, de los distintos sectores que conforman el Conjunto Histórico, así como, por el Plan General de Ordenación Urbanística vigente, se ha sintetizado la información a modo de base de datos con el fin de visualizar de manera resumida todo el panorama de la protección actual de estos 44 elementos.

Como se puede observar en la Tabla 3, la mayor parte de los edificios se encuentran con una protección nivel C. De este modo llega a reunir un total de 29 edificios, lo que supone un $66 \%$ del total de la muestra de estudio. Este nivel es el más común, principalmente, entre los planes redactados recientemente. El resto de edificios se sitúan en otros niveles de protección. Con el nivel máximo A no se encuentra ninguno de los edificios de la muestra. Por otro lado, con el grado B se encuentran 3 edificios, y en los grados más bajos 2 edificios en cada uno de ellos -D y E- suponiendo un 5\% de la muestra. 
Es por ello que la mayor parte de los edificios se sitúan en una protección de nivel medio, resultando un número reducido de casos en los niveles superiores o inferiores (Figura 5). Sin embargo, habría que destacar el porcentaje de edificios sin protección, los cuáles suponen un 18\% de la totalidad de elementos analizados.

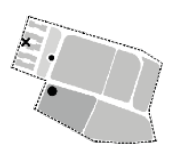

Sector 22. PEP 1994 + PGOU 2006 3 edificios, 2 protegidos

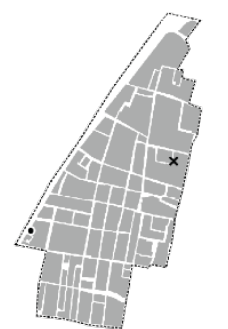

Sector 09. PEP 2000 + PGOU 2006 2 edificios, 1 protegido

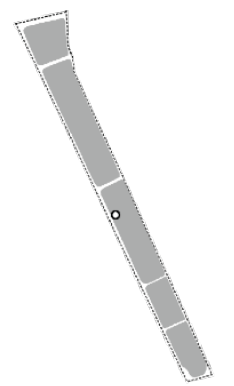

Sector 25. PEP 2004 + PGOU 2006 1 edificio, 1 protegido

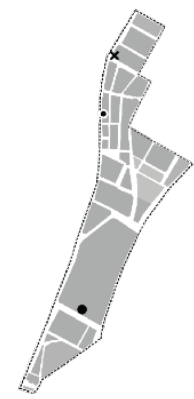

Sector 18. PEP 1995 + PGOU 2006 3 edificios, 2 protegidos

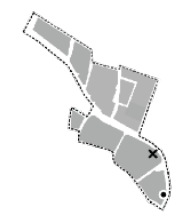

Sector 16 . PEP $2001+$ PGOU 2006 2 edificios, 1 protegido

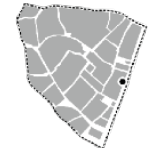

Sector 05 . PEP 2004 + PGOU 2006 1 edificio, 1 protegido

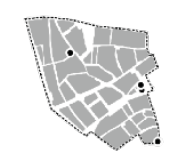

Sector 08.4. PEP 2013 + PGOU 2006 4 edificios, 4 protegidos
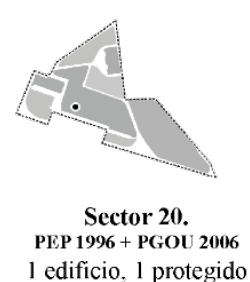

Sector 14 PEP 1999 + PGOU 200 1 edificio, 0 protegidos

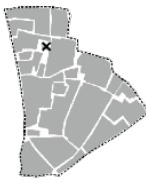

Sector 03 . PEP 2000 + PGOU 2006 1 edificio 0 protegido

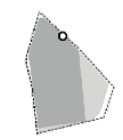

Sector 23. PEP 2002 + PGOU 2006 1 edificio, 1 protegido

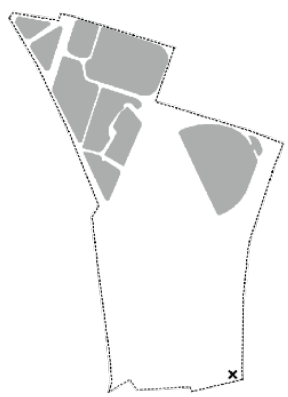

Sector 26 . PEP 2006 + PGOU 2006 1 edificio, 0 protegidos

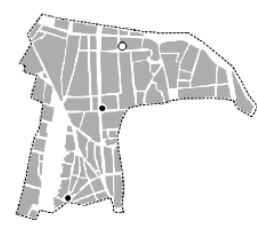

Sector 01. Sector 01.
PEP 2002 + PGOU 2006 3 edificios, 3 protegidos

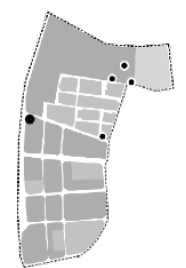

Sector 24. PEP 2003 + PGOU 2006 5 edificios, 5 protegidos

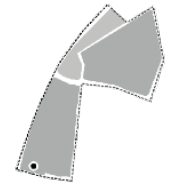
Sector 19.
PEP 2010 + PGOU 2006 1 edificio, 1 protegido

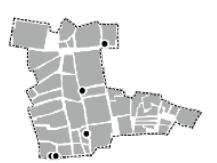

Sector 08.3. PEP 2010 + PGOU 2006 PEP 2010 + PGOU 2006
5 edificios, 5 protegidos

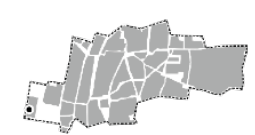

Sector 08.2. PEP 2013 + PGOU 2006 1 edificio, 1 protegido

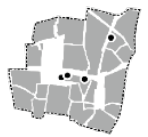

Sector 08.1. PEP 2014 + PGOU 2006 4 edificios, 4 protegidos

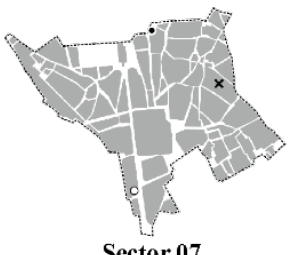

Sector 07. PGOU 2006 3 edificios, 2 protegidos

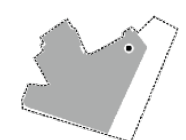

Sector 06.

PGOL 2006

1 edificio, 1 protegido
Nivel de protección

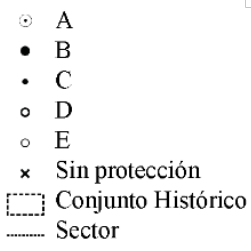

- C

$\times$ Sin protección

.......... Sector

Figura 4 - Edificios por sector y su nivel de protección según el Plan General de Ordenación Urbana (PGOU) de Sevilla. Fuente: Elaborado por los autores (2020) en base al PGOU de Sevilla (2006). 
Tabla 3 - Edificios según cada nivel de protección

\begin{tabular}{ccc}
\hline Nivel & Edificios & Porcentaje (\%) \\
\hline A: Integral & 0 & 0 \\
B: Global & 3 & 6,82 \\
C: Parcial grado 1 & 29 & 65,91 \\
D: Parcial grado 2 & 2 & 4,55 \\
E: Ambiental & 2 & 4,55 \\
Sin protección & 8 & 18,18 \\
\hline
\end{tabular}

Fuente: Autores (2020).

Del análisis de la localización de los 8 edificios desprotegidos se desprende que existe cierta tendencia a situarse en los sectores más periféricos de la ciudad histórica, a excepción del caso del sector 7 (Figura 6). Además, 6 de ellos pertenecen a los sectores con Planes Especiales de mayor antigüedad, 1 al sector sin Plan Especial y 1 a un plan aprobado en el mismo momento que el Plan General de Ordenación Urbana de 2006, el cual conserva la desprotección.

Podría considerarse reseñable que la mayor parte de los edificios vinculados a la etapa del Movimiento Moderno con valores patrimoniales, siendo el $81,82 \%$, se encuentran protegidos por el planeamiento urbanístico, al mismo tiempo que los menores grados de protección suponen un 9,10\% del total. Sin embargo, no habría que perder de vista que lo realmente alarmante en cuanto a este patrimonio es el total de elementos desprotegidos de la muestra analizada, lo cual implica a los 8 edificios mencionados previamente. Dicha desprotección no haría otra cosa que abundar en el avance de pérdida de valores de este patrimonio en caso de hipotéticas modificaciones o, en el peor de los casos, incrementar la lista de edificios desaparecidos.

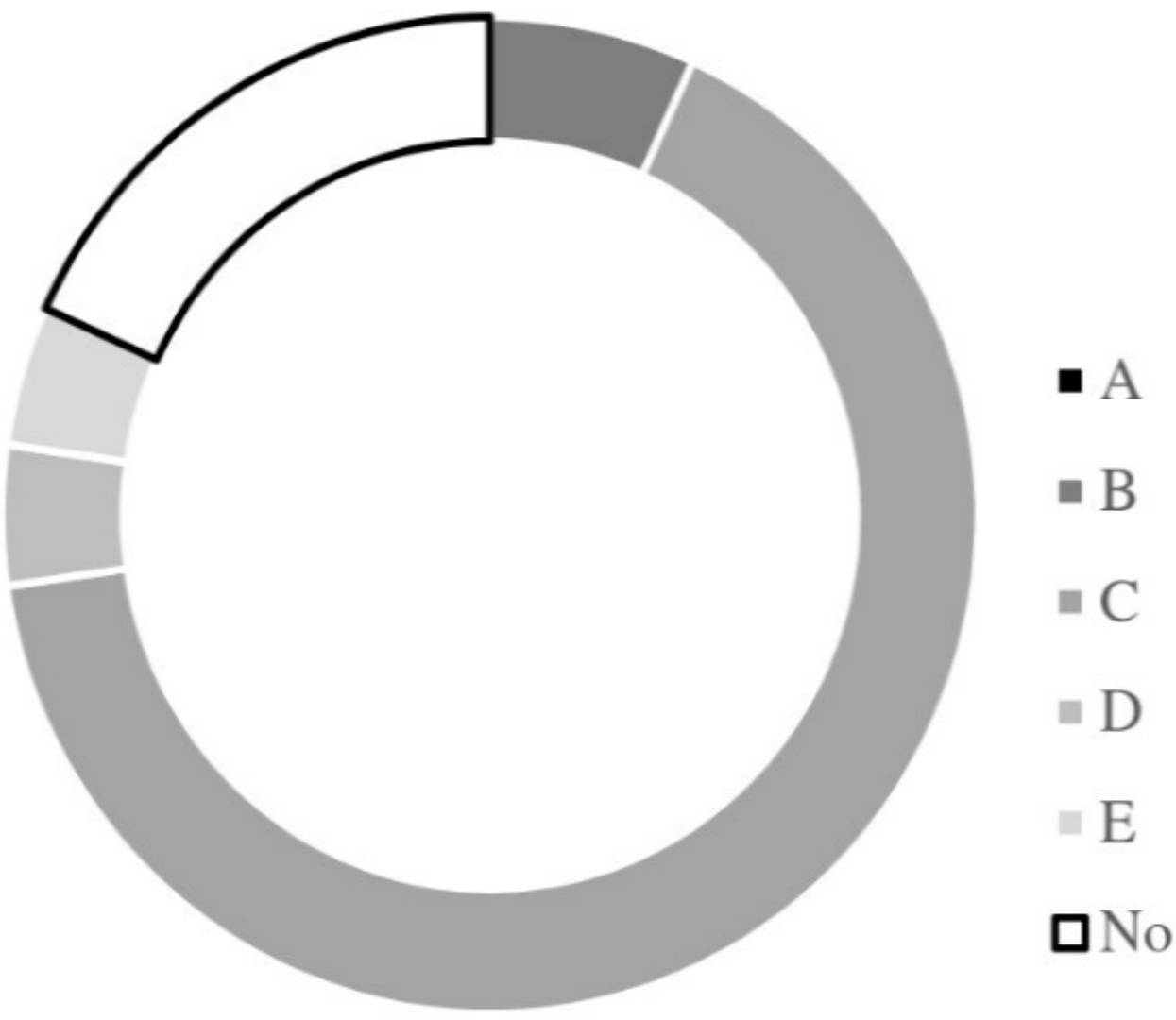

Figura 5 - Edificios según cada nivel de protección. Fuente: Autores (2020) 


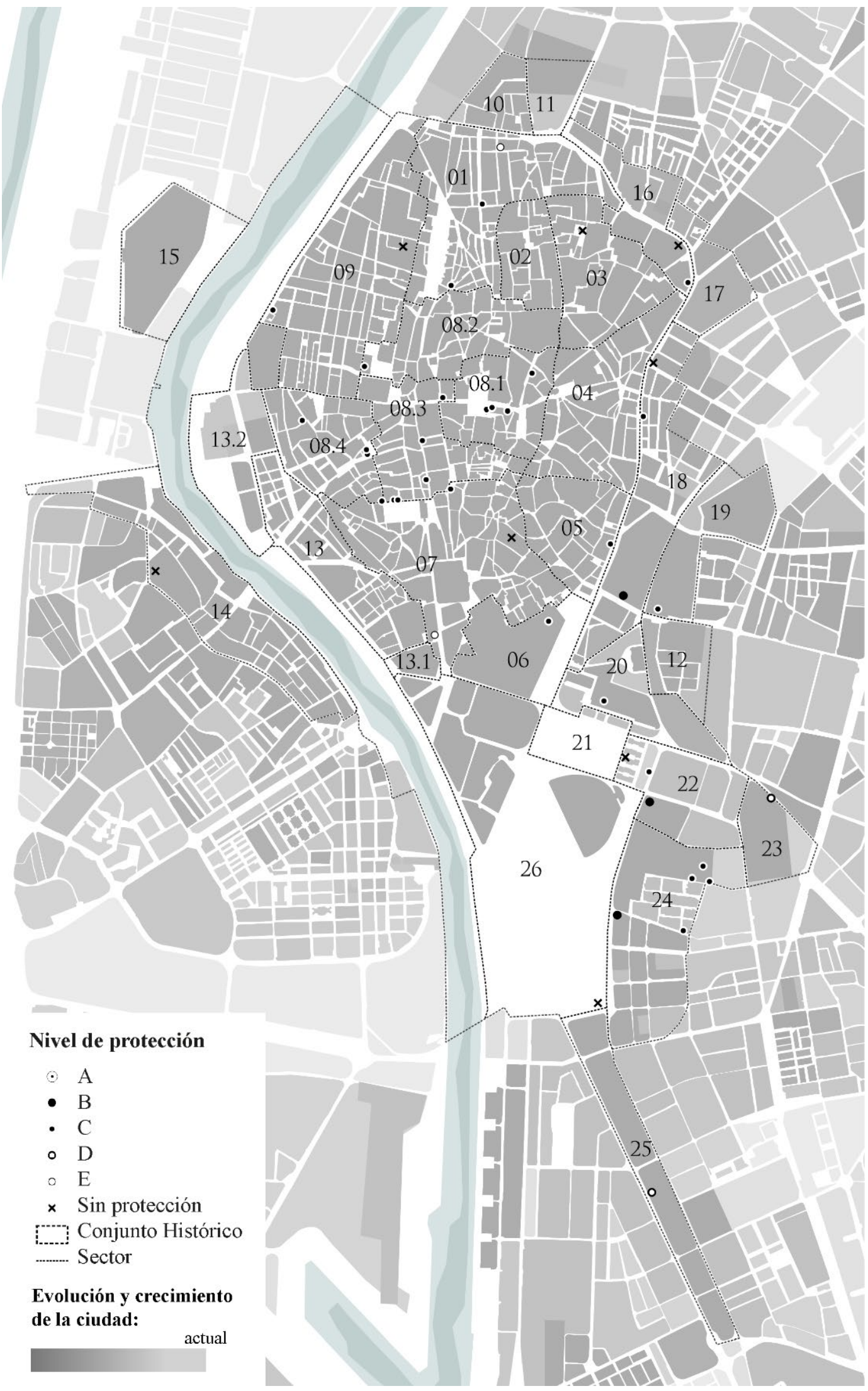

Figura 6 - Sectores del Conjunto Histórico de Sevilla. Nivel de protección de los edificios analizados a través del Plan General de Ordenación Urbanística de Sevilla (PGOU) y los Planes Especiales de Protección (PEP). Fuente: Elaborado por los autores (2020) en base al PGOU (Sevilla, 2006) y a los PEP. 


\section{Conclusiones}

La presente investigación muestra cómo la evolución en el concepto de patrimonio ha ido permitiendo la incorporación de una mayor diversidad de bienes culturales, tanto materiales como inmateriales, propiciando el reconocimiento de edificios del Movimiento Moderno como Patrimonio Cultural. Este hecho se ha evidenciado a través del recorrido que los organismos internacionales, nacionales, regionales y locales han realizado desde el último tercio del siglo pasado. Avances que han tenido repercusión en el caso de los edificios construidos en Sevilla entre 1925 y 1975.

Si bien la muestra analizada en este artículo está conformada por edificios, el enfoque eminentemente urbano utilizado sirve para dibujar un panorama cuya amplitud supera la visión del elemento unitario. De este modo, se han evidenciado las diferencias presentes tanto en la inserción de estas piezas en la ciudad histórica como las desiguales protecciones patrimoniales entre los edificios según el fragmento del Conjunto Histórico en el que se sitúen. Por otro lado, en relación con la superación del objeto mencionada, junto a la apertura experimentada por el concepto de patrimonio, resulta pertinente abogar por investigaciones que amplíen la óptica hacia los espacios públicos modernos amparado bajo la noción de patrimonio paisajístico contemporáneo (Rey Pérez \& Tabacow, 2013).

Igualmente, la investigación pone de manifiesto que el planeamiento urbanístico se muestra como una herramienta de utilidad a la hora de proteger este patrimonio. La oportunidad de estos instrumentos reside en que nacen de la administración pública local como ente más cercano a estos edificios. Sin embargo, para el caso de Sevilla, los rápidos avances señalados en el concepto de patrimonio no se han visto reflejados en la actualización de los Planes Especiales de Protección, así como en el Plan General de la ciudad. La antigüedad con la que cuentan algunos de estos planes o la inexistencia en algunos sectores de la ciudad, no hacen más que abundar en el deseable avance hacia una mayor versatilidad de esta herramienta urbanística, así como en la necesidad de renovación de los Catálogos de Protección de manera periódica.

La ausencia de edificios catalogados con nivel A, o el bajo número de grado B muestran la diferencia que existe aún con los que tienen mayor recorrido histórico. Esto vislumbra la consideración, por parte de las administraciones competentes en la materia, de la arquitectura nacida del Movimiento Moderno como un patrimonio no situado al mismo nivel que el de etapas previas. A ello habría que sumar lo que supone una protección media como sucede en Sevilla, ya que con el grado de protección C se permiten modificaciones sustanciales, las cuales pueden propiciar la pérdida de valores patrimoniales específicos de estos edificios. Algo que se vería incrementado con los protegidos con nivel D o E.

Sin embargo, la mayor preocupación surge de la desprotección de un reseñable número de ellos. Si las modificaciones suponen un peligro en la pérdida de valores, la amenaza de desaparición viene a incrementar las posibles pérdidas de patrimonio cultural del Movimiento Moderno. Una vez asentado el reconocimiento de este fragmento de la historia reciente como parte de nuestro patrimonio, el reto para el siglo XXI sería la actualización de los criterios y de las figuras del planeamiento para asegurar la pervivencia de este patrimonio en el futuro.

En cualquier caso, y tal como indica Ana Tostões (2015), la compleja tarea de conservar este patrimonio sólo podrá ser posible incrementando el grado de entendimiento y aprecio que la sociedad en su conjunto tiene del Movimiento Moderno. Cuestión para la cual habrá que ahondar en acciones y estrategias de divulgación de este patrimonio, ya que el aumento en el conocimiento de la producción del pasado siglo XX contribuirá a un reconocimiento generalizado de estos bienes como legado a conservar para las generaciones venideras. En este sentido, el hecho de que un cuantioso número de estos edificios se localicen en entornos patrimoniales históricos, zonas que gozan de un amplio reconocimiento social y turístico, se presenta como una oportunidad para incluir también el patrimonio contemporáneo en los circuitos turísticos habituales, especialmente pertinente en aquellos casos de un público especializado. Ahondando, con ello, en el reconocimiento y, por ende, en la salvaguarda de estas arquitecturas tanto por sociedad local como por la foránea. 


\section{Agradecimientos}

La investigación ha recibido financiación del Ministerio de Ciencia, Innovación y Universidades del Gobierno de España (FPU17/03701) y el apoyo de la Universidad de Sevilla.

\section{Referencias}

Alonso García, E., Rincón Borrego, I., Pérez Barreiro, S., \& Cebrián Renedo, S. (2018). Arquitectura y cine: hacia una estrategia de difusión y promoción del patrimonio cultural. In XI Congreso Internacional AR\&PA (pp. 597-604). Valladolid: LAB/PAP.

Andalucía. Junta de Andalucía. (1991, 13 de julio). Ley 1/1991, de 3 de julio, de Patrimonio Histórico de Andalucía. Sevilla: Boletín Oficial de la Junta de Andalucía, n. 59, p. 5573-5586.

Andalucía. Junta de Andalucía. (2002, 31 de diciembre). Ley 7/2002, de 17 de diciembre, de Ordenación Urbanística de Andalucía. Sevilla: Boletín Oficial de la Junta de Andalucía, n. 154, p. 25.084-25.145.

Andalucía. Junta de Andalucía. (2007, 19 de diciembre). Ley 14/2007, de 26 de noviembre, del Patrimonio Histórico de Andalucía. Sevilla: Boletín Oficial de la Junta de Andalucía, n. 248, p. 6-28.

Andalucía. Junta de Andalucía. (2020a). Guía digital. Sevilla: Instituto Andaluz del Patrimonio Histórico. Recuperado el 21 de enero de 2020, de https://guiadigital.iaph.es/

Andalucía. Junta de Andalucía. (2020b). Catálogo General del Patrimonio Histórico Andaluz. Recuperado el 10 de julio de 2020, de https://www.juntadeandalucia.es/organismos/culturaypatrimoniohistorico/areas/bienesculturales/catalogo-pha.html

Andalucía. Junta de Andalucía. (2020c). Infraestructura de datos espaciales de Andalucía. Recuperado el 1 de noviembre de 2018, de http://www.ideandalucia.es/clientedescarga/

Becerra García, J. M. (2012). La protección del patrimonio arquitectónico contemporáneo en Andalucía. In R. Fernández-Baca Casares \& V. Pérez Escolano (Coords.), Cien años de arquitectura en Andalucía. El Registro Andaluz de Arquitectura Contemporánea, 1.900-2.000 (pp. 18-21). Sevilla: Instituto Andaluz de Patrimonio Histórico.

De Jonge, W. (2017). Sleeping beauty. In Kuipers, M., \& de Jonge, W. (Eds.), Designing from Heritage. Strategies for Conservation and Conversion (pp. 14-29.). Delft: TU Delft - Heritage and Architecture.

Docomomo Ibérico. (2020). Los registros del Movimiento Moderno. Barcelona: DOCOMOMO Ibérico. Recuperado el 21 de enero de 2020, de

http://www.docomomoiberico.com/index.php?option=com_k2\&view=itemlist\&layout=category\&task=category\&i $\mathrm{d}=12$ \&Itemid=55\&lang=es

Docomomo. (1990). Declaración de Eindhoven. Eindhoven: DOCOMOMO.

España. Ministerio de Educación, Ciencia y Deportes - MECD. (2015). Plan Nacional de Conservación del Patrimonio Cultural del Siglo XX. Madrid: Subdirección General de Documentación y Publicaciones, Secretaría General Técnica.

España. Ministerio de Instrucción Pública y Bellas Artes. (1933, 15 de mayo). Ley relativa al Patrimonio Artístico Nacional. Madrid: Gaceta de Madrid, n. 145, p. 1393-1399.

Europa. Consejo de Europa, Comité de Ministros. (1991, 9 de septiembre). Recomendación (91) 13 del Comité de Ministros a los Estados miembros relativa a la protección del patrimonio arquitectónico del siglo XX. Bruselas:

Consejo de Europa, Comité de Ministros.

Fariña Tojo, J. (2000). La Protección del Patrimonio Urbano. Instrumentos normativos. Madrid: Akal.

Fernández Salinas, V. (1992). La reforma interior de Sevilla entre 1940 y 1959. Sevilla: Consejería de Obras Públicas y Transportes, Universidad de Sevilla. 
Fernández-Baca Casares, R., \& Pérez Escolano, V. (Coords.) (2012). Cien años de arquitectura en Andalucía. El Registro Andaluz de Arquitectura Contemporánea, 1900-2000. Sevilla: Instituto Andaluz de Patrimonio Histórico.

Flores López, C. (1989). Arquitectura española contemporánea (2nd ed.). Madrid: Aguilar.

García-Gutiérrez Mosteiro, J. (2011). Consideraciones sobre algunos caracteres de la arquitectura del siglo XX y su incidencia en los criterios de salvaguardia patrimonial. In Conferencia Internacional sobre Criterios de intervención en el patrimonio arquitectónico del siglo XX (CAH20thC) (pp. 145-150). Madrid: Subdirección General de Publicaciones, Información y Documentación, Secretaría General Técnica, Ministerio de Cultura.

Getty Conservation Institute. (2018). Conserving modern architecture initiative. Recuperado el 11 de julio de 2020, de getty.edu/conservation/our_projects/field_projects/cmai/cmai_overview.html

Instituto de Estadística y Cartografía de Andalucía - IECA. (2020). Evolución histórica de la población de Andalucía. Población de los municipios de la provincia de Sevilla según los censos de 1787 a 2001. Sevilla: IECA. Recuperado el 21 de enero de 2020, de

https://www.juntadeandalucia.es/institutodeestadisticaycartografia/ehpa/ehpaTablas.htm

Instituto Nacional de Estadística de España - INE. (2020). Cifras oficiales de población de los municipios españoles: Revisión del Padrón Municipal. Madrid: INE. Recuperado el 21 de enero de 2020, de https://www.ine.es/dynt3/inebase/index.htm?padre=525

Internacional Scientific Committee - ISC20C. (2011). Documento de Madrid. Criterios de conservación del Patrimonio Arquitectónico del Siglo XX. Madrid: Comité Científico Internacional del Patrimonio del Siglo XX de ICOMOS.

Madrid. Jefatura del Estado. (1985, 29 de junio). Ley 16/1985, de 25 de junio, del Patrimonio Histórico Español. Madrid: Boletín Oficial del Estado, n. 155.

Mosquera Adell, E., \& Pérez Cano, M. T. (1990). La Vanguardia Imposible: quince visiones de arquitectura contemporánea. Sevilla: Consejería de Obras Públicas y Transportes.

Navas-Carrillo, D. (2020). Patrimonio y ciudad. Barriadas residenciales en ciudades medias del litoral: un análisis comparado entre Andalucía, Portugal y los Países Bajos (Tesis doctoral). Universidad de Sevilla, Sevilla.

Navas-Carrillo, D., Gómez-de-Cózar, J. C., \& Pérez-Cano, M. T. (2019). Geographic information systems (GIS) and building information modeling (BIM): tools for assessing the cultural values of mass housing neighbourhoods in medium-sized cities of Andalusia. In P. Ortiz Calderón, F. Pinto Puerto, Verhagen, P., \& Prieto, A. J. (Eds.), Science and Digital Technology for Cultural Heritage-Interdisciplinary Approach to Diagnosis, Vulnerability, Risk Assessment and Graphic Information Models (pp. 104-108.). Leiden: Taylor \& Francis Group.

http://dx.doi.org/10.1201/9780429345470-19.

Pérez Escolano, V. (1999). Arquitectura MODERNA como PATRIMONIO. In Instituto Andaluz de Patrimonio Histórico. Cuadernos. La arquitectura moderna en Andalucía: un patrimonio por documentar y conservar. La experiencia DOCOMOMO (pp. 12-17). Sevilla: Consejería de Cultura de la Junta de Andalucía, Instituto Andaluz de Patrimonio Histórico.

Pérez Escolano, V., Pérez Cano, M. T., Mosquera Pérez, E., \& Moreno Pérez, J. R. (1986). 50 años de Arquitectura en Andalucía: 1936-1986. Sevilla: Consejería de Obras Públicas y Transportes.

Praga. Comisión de Resolución. (1971). Declaración de Praga. Resolución para la protección de los monumentos culturales de los siglos XIX y XX. Praga: Comisión de Resolución.

Rey Pérez, J., \& Tabacow, J. (2013). Un análisis de la evolución de las intervenciones urbanas de Roberto Burle Marx en Río de Janeiro. Arquiteturarevista, 9(1), 20-36. http://dx.doi.org/10.4013/arq.2013.91.03.

Rodríguez-Lora, J. A. (2018). La protección del patrimonio contemporáneo, arquitectura en torno al Movimiento Moderno en Sevilla, una revisión urbano-patrimonial tres décadas después (Trabajo Fin de Máster). Universidad de Sevilla, Sevilla.

Rodríguez-Lora, J. A., Navas-Carrillo, D., \& Pérez-Cano, T. (2018). Effective protection of contemporary heritage of twentieth century architecture: the case of Seville. In A. de Carvalho Antunes, \& M. Müller (Eds.), New Perspectives 
in Interdisciplinary Cultural Heritage Studies. Contributions of the European Students' Association for Cultural Heritage in the European Year of Cultural Heritage 2018 (pp. 113-127). Oeiras: Mazu Press.

Sarabia Sánchez, J. (1998). Collaciones históricas de Sevilla. Sevilla: Joaquín Sarabia Sánchez.

Sevilla. Ayuntamiento de Sevilla. (2006, 7 de septiembre). Plan General de Ordenación Urbanística de Sevilla. Resolución Consejería de Obras Públicas y Vivienda de 19 de julio de 2006. Sevilla: Boletín Oficial de la Junta de Andalucía, n. 174.

Sevilla. Ayuntamiento de Sevilla. (2020). Planeamiento desarrollo. Recuperado el 10 de julio de 2020, de https://www.urbanismosevilla.org/planeamiento/planeamiento-desa

Tejido Jiménez, J. (2016). La demolición a gran escala como técnica de intervención urbana. La apertura de la Avenida de la Constitución de Sevilla (1906-1927). Informes de la Construcción, 68(541), e137.

http://dx.doi.org/10.3989/ic.15.045.

Tostões, A. (2015). Património Moderno: a conservaçao e a reutilizaçao como um recurso sustentável. Joelho. Revista de Cultura Arquitectónica: A Questão do Património, 6, 16-24. https://doi.org/10.14195/1647-8681_6_12.

United Nations Educational, Scientific and Cultural Organization - UNESCO (2003). World heritage papers (No. 5). Paris: UNESCO.

Editor: Fábio Duarte

Recibido: Mayo 04, 2020

Aprobado: Jul. 272020 